This is an electronic reprint of the original article. This reprint may differ from the original in pagination and typographic detail.

\author{
Author(s): Benitez, J.Y.; Franzen, K.Y.; Hodgkinson, A.; Loew, T.; Lyneis, C.M.; Phair, L.; Saba, J.; \\ Strohmeier, M.; Tarvainen, Olli
}

Title: $\quad$ Recent progress on the superconducting ion source VENUS

Year: $\quad 2012$

Version:

Please cite the original version:

Benitez, J.Y., Franzen, K.Y., Hodgkinson, A., Loew, T., Lyneis, C.M., Phair, L., Saba, J., Strohmeier, M., \& Tarvainen, O. (2012). Recent progress on the superconducting ion source VENUS. Review of Scientific Instruments, 83(2), 02A311. https://doi.org/10.1063/1.3662119

All material supplied via JYX is protected by copyright and other intellectual property rights, and duplication or sale of all or part of any of the repository collections is not permitted, except that material may be duplicated by you for your research use or educational purposes in electronic or print form. You must obtain permission for any other use. Electronic or print copies may not be offered, whether for sale or otherwise to anyone who is not an authorised user. 


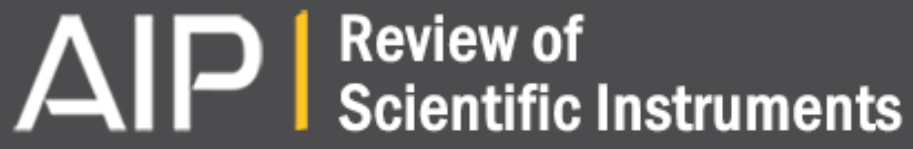

\section{Recent progress on the superconducting ion source VENUSa)}

J. Y. Benitez, K. Y. Franzen, A. Hodgkinson, T. Loew, C. M. Lyneis, L. Phair, J. Saba, M. Strohmeier, and O. Tarvainen

Citation: Review of Scientific Instruments 83, 02 A311 (2012); doi: 10.1063/1.3662119

View online: http://dx.doi.org/10.1063/1.3662119

View Table of Contents: http://scitation.aip.org/content/aip/journal/rsi/83/2?ver=pdfcov

Published by the AIP Publishing

\section{Articles you may be interested in}

Recent development of RIKEN $28 \mathrm{GHz}$ superconducting electron cyclotron resonance ion sourcea)

Rev. Sci. Instrum. 85, 02 A953 (2014); 10.1063/1.4848976

The third generation superconducting $28 \mathrm{GHz}$ electron cyclotron resonance ion source VENUS (invited)a)

Rev. Sci. Instrum. 81, 02A201 (2010); 10.1063/1.3271135

Production of highly charged ion beams with SECRALa)

Rev. Sci. Instrum. 81, 02 A318 (2010); 10.1063/1.3267306

ARTEMIS-B: A room-temperature test electron cyclotron resonance ion source for the National Superconducting Cyclotron Laboratory at Michigan State University

Rev. Sci. Instrum. 77, 03A322 (2006); 10.1063/1.2165749

VENUS: The next generation ECR ion source

AIP Conf. Proc. 600, 219 (2001); 10.1063/1.1435237

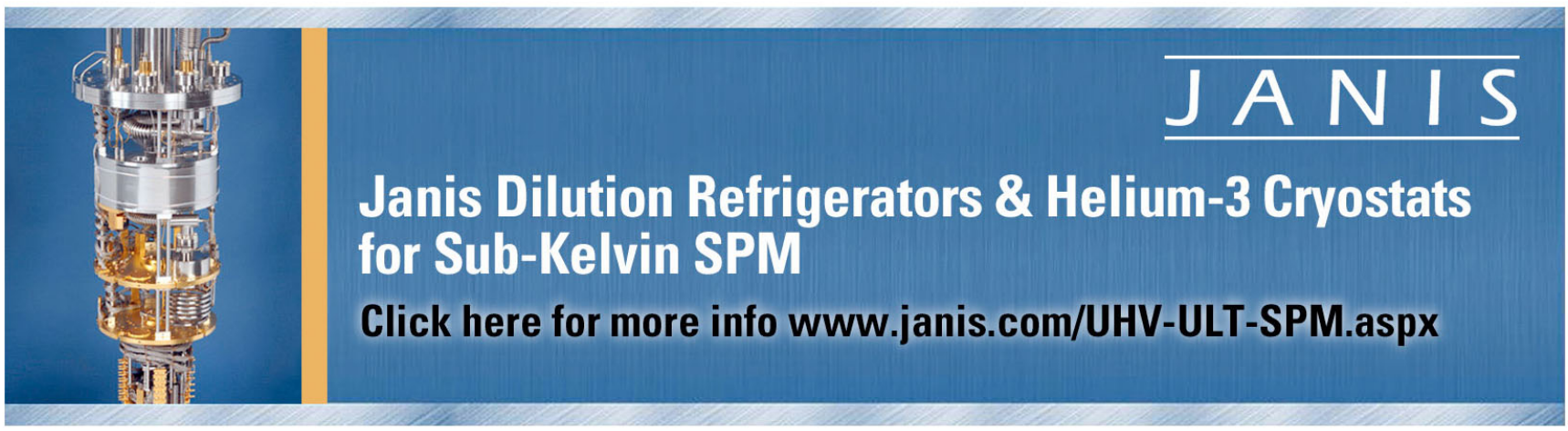




\title{
Recent progress on the superconducting ion source VENUS ${ }^{a)}$
}

\author{
J. Y. Benitez, ${ }^{1, b)}$ K. Y. Franzen, ${ }^{1}$ A. Hodgkinson, ${ }^{1}$ T. Loew, ${ }^{1}$ C. M. Lyneis, ${ }^{1}$ L. Phair, ${ }^{1}$ \\ J. Saba, ${ }^{1}$ M. Strohmeier, ${ }^{1}$ and O. Tarvainen ${ }^{2}$ \\ ${ }^{1}$ Nuclear Science Division, Lawrence Berkeley National Laboratory, Berkeley, California 94720, USA \\ ${ }^{2}$ Accelerator Laboratory, Department of Physics, University of Jyväskylä, FIN-40014, Finland
}

(Presented 13 September 2011; received 12 September 2011; accepted 16 October 2011; published online 6 February 2012)

\begin{abstract}
The $28 \mathrm{GHz}$ Ion Source VENUS (versatile ECR for nuclear science) is back in operation after the superconducting sextupole leads were repaired and a fourth cryocooler was added. VENUS serves as an $\mathrm{R} \& \mathrm{D}$ device to explore the limits of electron cyclotron resonance source performance at $28 \mathrm{GHz}$ with its $10 \mathrm{~kW}$ gryotron and optimum magnetic fields and as an ion source to increase the capabilities of the 88-Inch Cyclotron both for nuclear physics research and applications. The development and testing of ovens and sputtering techniques cover a wide range of applications. Recent experiments on bismuth demonstrated stable operation at $300 \mathrm{e} \mu \mathrm{A}$ of $\mathrm{Bi}^{31+}$, which is in the intensity range of interest for high performance heavy-ion drivers such as FRIB (Facility for Rare Isotope Beams). In addition, the space radiation effects testing program at the cyclotron relies on the production of a cocktail beam with many species produced simultaneously in the ion source and this can be done with a combination of gases, sputter probes, and an oven. These capabilities are being developed with VENUS by adding a low temperature oven, sputter probes, as well as studying the RF coupling into the source. () 2012 American Institute of Physics. [doi:10.1063/1.3662119]
\end{abstract}

\section{VENUS ECR ION SOURCE}

The VENUS (versatile ECR for nuclear science) electron cyclotron resonance (ECR) ion source, shown in Fig. 1, is a fully superconducting ion source. The three solenoids and the sextupole coils are made out of Niobium-Titanium alloy embedded in a Copper matrix. VENUS is both an operating ion source for Lawrence Berkeley National Lab's 88-Inch Cyclotron as well as prototype for FRIB. The source has been an invaluable tool in expanding the limits of ECR ion sources, in studying the scaling laws formulated by Geller, ${ }^{1}$ and provides a starting point for the development of a 4th Generation ECR ion source. ${ }^{2}$ Its operating parameters are listed in Table I.

Last year $75 \%$ of the total beams delivered to the 88 -Inch Cyclotron facility's users came from the $14 \mathrm{GHz}$ AECR-U ion source. These beams include cocktails ${ }^{3}$ and high intensity metal ion beams. Since VENUS' first re-commissioning beam on July 2010, after the repair of one of the sextupole leads, ${ }^{4}$ one goal has been to integrate the VENUS ECR ion source into regular operation in order to provide relief and serve as a back up to the AECR-U ion source. This includes the fabrication of a low temperature oven, which will be discussed below, the development of a multi-metal sputter probe, currently under way, and the development of a high temperature oven capable of reaching $2300^{\circ} \mathrm{C}$, also discussed below. The low temperature and high temperature ovens are needed to produce high intensity ion beams for the 88-Inch Cyclotron's Heavy Element research. The low temperature

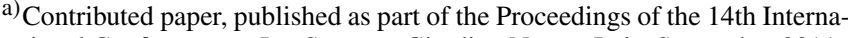
tional Conference on Ion Sources, Giardino Naxos, Italy, September 2011.

b) Author to whom correspondence should be addressed. Electronic mail: jybenitez@lbl.gov.
}

oven can also be used to produce ${ }^{209} \mathrm{Bi}^{41+}$, which is needed in the $4.5 \mathrm{MeV} /$ nucleon cocktail.

\section{HIGH TEMPERATURE OVEN}

The VENUS high temperature oven is installed axially as shown in Fig. 2. It is intended to be run up to $2300^{\circ} \mathrm{C}$ by resistive heating. The combination of high $\mathrm{DC}$ oven current, needed to reach $2000{ }^{\circ} \mathrm{C}$, and the strong $4 \mathrm{~T}$ magnetic field at the VENUS injection end exerts a transverse force on the oven causing undesirable movement of the oven components. ${ }^{5}$

A test of the oven in the source at $254 \mathrm{~A}, 407 \mathrm{~W}$ of total power, and a 3.4 $\mathrm{T}$ injection field resulted in a failure of the Tungsten crucible. The water cooled copper oven leads that carry the current to the oven become soft and bend, as shown in Figs. 3(a) and 3(b), shearing off the refractory metal oven stem which sits in the copper housing.

The oven was tested in a test stand while monitoring the temperature of the copper leads, at the position shown with a star in Fig. 3(a). This confirmed there was insufficient cooling. As shown in Fig. 4, even at $300 \mathrm{~W}$ power, the copper leads' temperature exceeded $100^{\circ} \mathrm{C}$ indicating the onset of boiling water and loss of efficient heat transfer. The power needed to reach $2000^{\circ} \mathrm{C}$ is $\sim 1100 \mathrm{~W}$.

A modification was made to the $\mathrm{Cu}$ leads, as shown in Fig. 3(c), to provide a larger surface area of $\mathrm{Cu}$ for heat transfer. The results in Fig. 4 show a significant improvement in the lead cooling. At a power of $1100 \mathrm{~W}$ the $\mathrm{Cu}$ leads only reached $80^{\circ} \mathrm{C}$. The high temperature oven then was retested in the VENUS ion source to produce a ${ }^{48} \mathrm{Ti}$ beam. The oven was run up to $315 \mathrm{~A}, 565 \mathrm{~W}$ in a $3.4 \mathrm{~T}$ injection magnetic field successfully. Figures 3(c) and 3(d) show that the oven after testing did not bend. The oven was run for three con- 


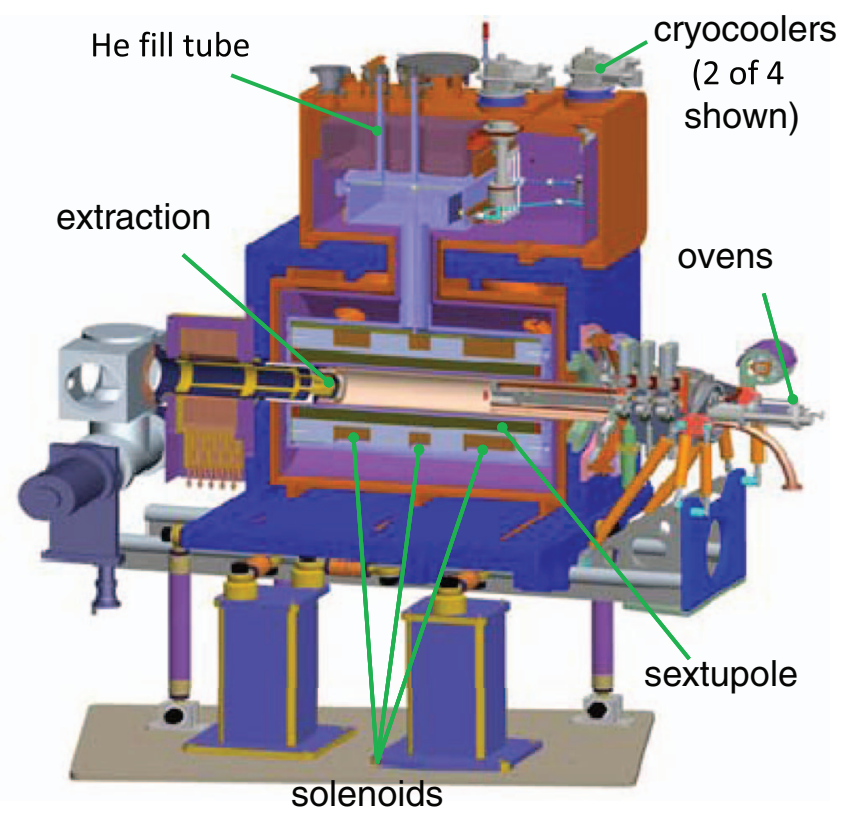

FIG. 1. (Color online) Layout of the VENUS ECR ion source.

secutive days at an average output of $75 \mathrm{e} \mu \mathrm{A}$ of ${ }^{48} \mathrm{Ti}^{14+}$. Figure 5 shows a spectrum taken while running ${ }^{48} \mathrm{Ti}$. The total consumption rate was $2.9 \mathrm{mg} / \mathrm{h}$.

\section{LOW TEMPERATURE OVEN}

The VENUS low temperature oven, shown in Fig. 6, is designed to reach temperatures no higher than $650^{\circ} \mathrm{C}$. Using a Dalton Watt-Flex Cartridge Heater, ${ }^{6}$ the copper oven housing the material is heated while simultaneously monitoring the temperature with a thermocouple. The low temperature oven is inserted axially, in place of the high temperature oven, shown in Fig. 2, and its support assembly is water cooled.

The low temperature oven was tested successfully in the VENUS ion source using ${ }^{40} \mathrm{Ca}$. Figure 7 shows a spectrum taken while running ${ }^{40} \mathrm{Ca}$ and producing $400 \mathrm{e} \mu \mathrm{A}$ of ${ }^{40} \mathrm{Ca}^{11+}$. This is an important result for us since $\mathrm{Ca}$ is a highly coveted beam by the Berkeley Gas-filled Separator group, who request $2 \mathrm{p} \mu \mathrm{A}$ of beam current on target. Work is being done to maximize the transport from the ion sources to the experimenter. The total consumption rate for the oven was $4 \mathrm{mg} / \mathrm{h}$.

\section{RECENT BEAM INTENSITIES}

Shortly after its re-commissioning in July 2010 VENUS was already showing promising results. ${ }^{4}$ Table II, which

TABLE I. VENUS ECR ion source operating parameters.

\begin{tabular}{lc}
\hline \hline Maximum injection field, on axis & $4.0 \mathrm{~T}$ \\
Maximum extraction field, on axis & $3.0 \mathrm{~T}$ \\
Maximum radial field, at wall & $2.2 \mathrm{~T}$ \\
$18 \mathrm{GHz}$ maximum power & $2 \mathrm{~kW}$ \\
$28 \mathrm{GHz}$ maximum power & $10 \mathrm{~kW}$ \\
\hline \hline
\end{tabular}

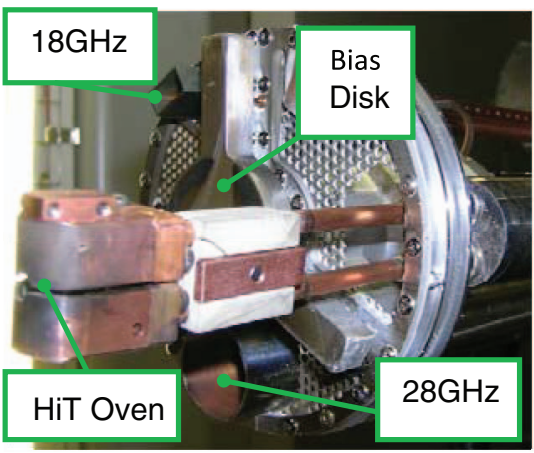

FIG. 2. (Color online) The VENUS injection. Shown is the high temperature oven, bias disk, and the 18 and $28 \mathrm{GHz}$ waveguides.
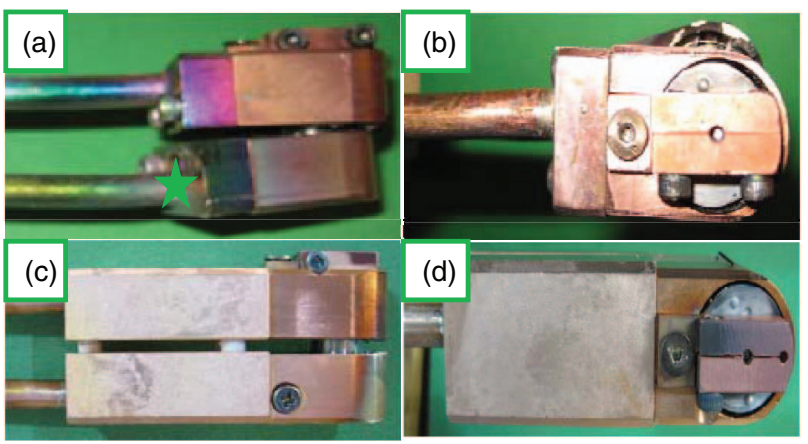

FIG. 3. (Color online) The side view (a) and top down view (b) of the HiT oven show the $\mathrm{Cu}$ oven leads bend when run under high currents and in the presence of a high magnetic field. The side view (c) and top down view (d) after modifying the $\mathrm{Cu}$ leads and testing the oven show an intact oven.

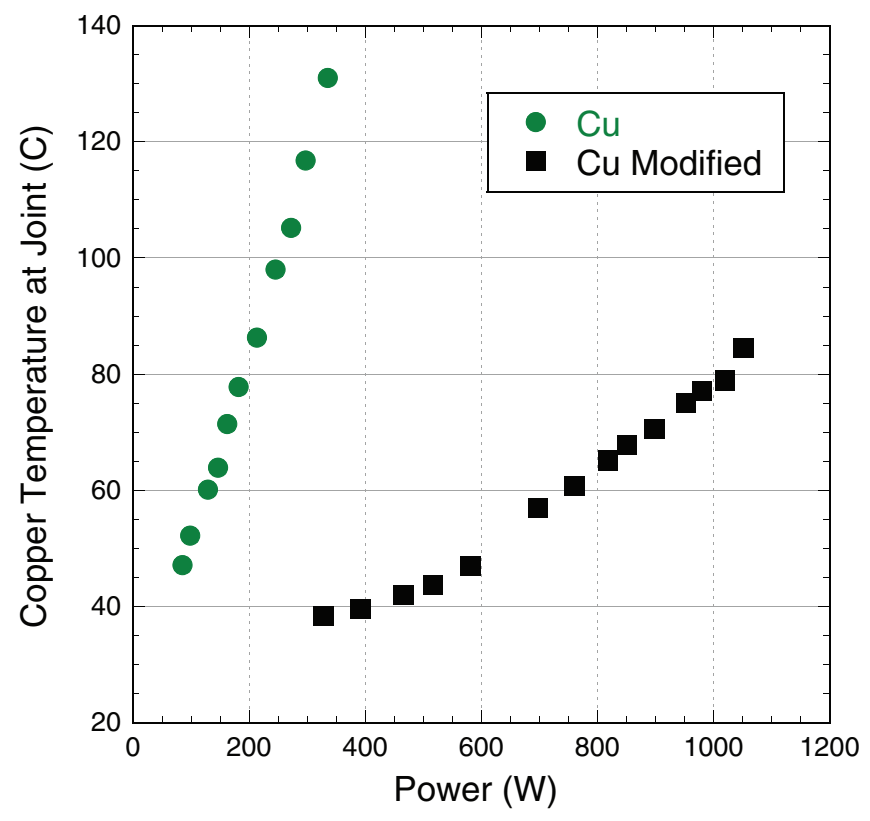

FIG. 4. (Color online) Original and modified copper leads temperature. 


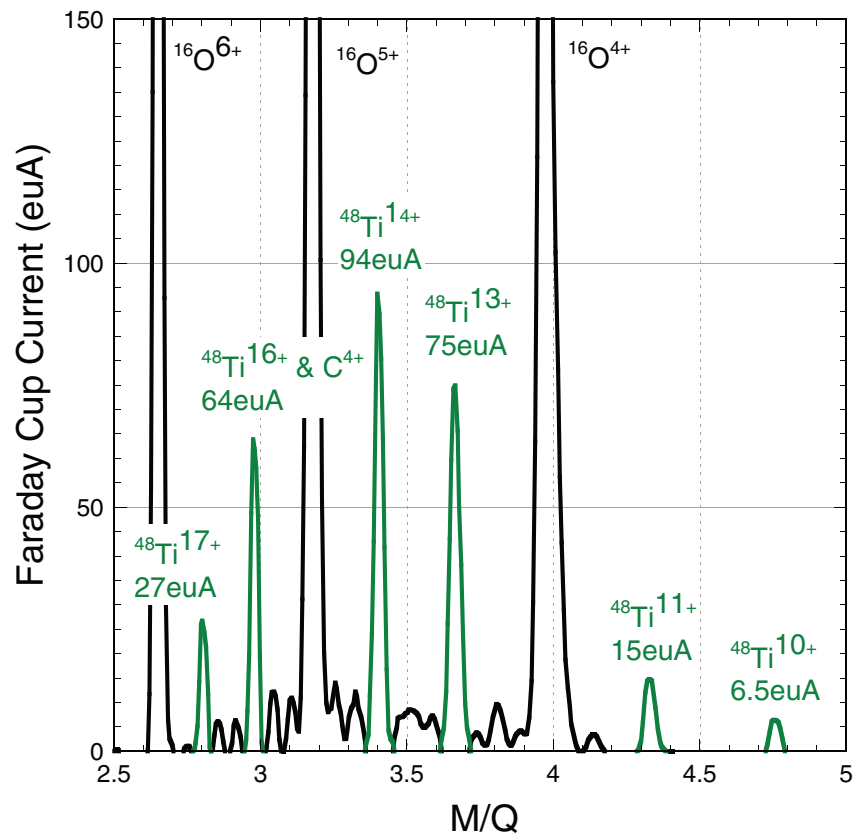

FIG. 5. (Color online) $\mathrm{A}^{48} \mathrm{Ti}$ spectrum produced by VENUS using the modified high temperature oven.

lists recent intensities and hallmark beams, demonstrates that VENUS continues to expand its capabilities. With the new low temperature oven and redesigned high temperature oven new beams can be tested.

\section{RF COUPLING}

The VENUS RF coupling system has both $18 \mathrm{GHz}$ and $28 \mathrm{GHz}$ waveguide antennas, which are used to inject RF power and shown in Fig. 8. The $18 \mathrm{GHz}$ antenna was recently modified with a $141 \mathrm{~mm}$ extension terminated with a $30^{\circ}$ bevel. This modification reduced the $\mathrm{CW}$ reflection coefficient measured with plasma in the chamber from about $8 \%$ to about $1 \%$ and it directs to first pass RF power from the antenna onto the plasma chamber axis at the location of the ECR zone to improve the absorption of power.

The $18 \mathrm{GHz} 2.0 \mathrm{~kW}$ klystron amplifier can be pulsed to make transient measurements. For these experiments the VENUS waveguide systems were reconfigured to measure cross coupling of 18 and $28 \mathrm{GHz}$ with diode detectors as

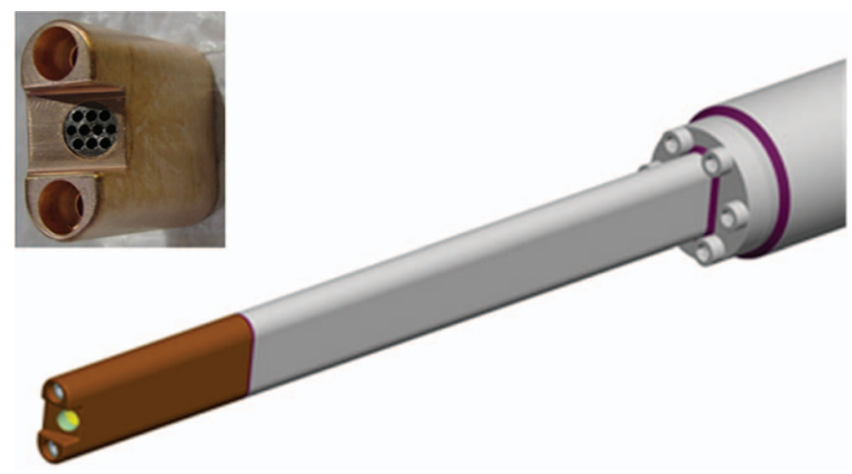

FIG. 6. (Color online) The VENUS low temperature oven.

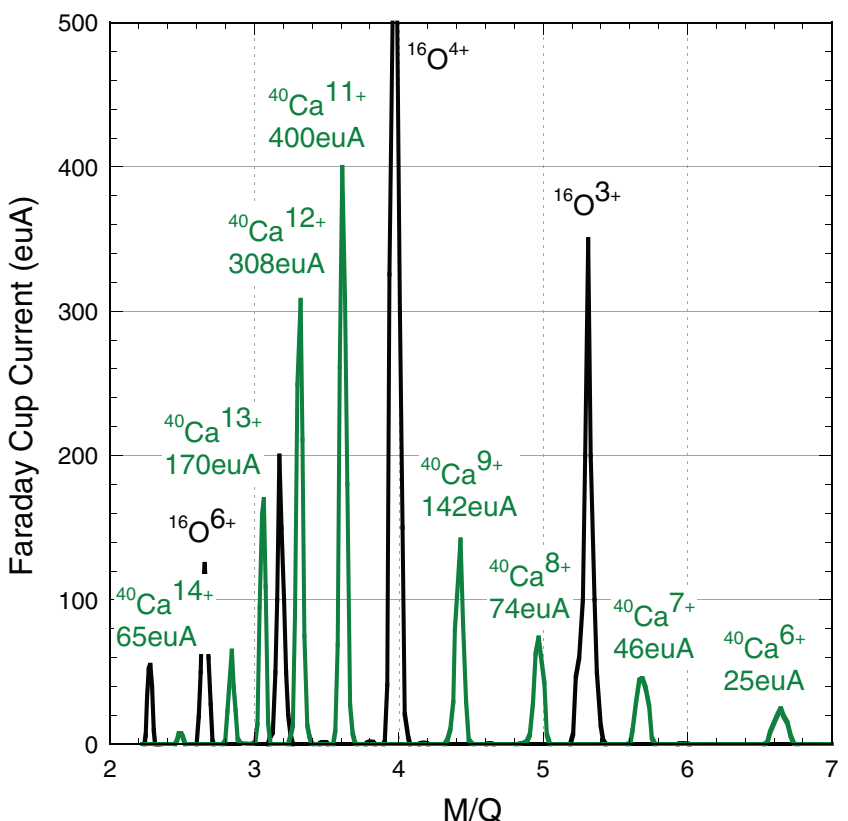

FIG. 7. (Color online) $\mathrm{A}{ }^{40} \mathrm{Ca}$ spectrum produced by VENUS using the low temperature oven.

TABLE II. Recent VENUS results.

\begin{tabular}{lccc}
\hline \hline Ion & Charge state & Intensity $(\mathrm{e} \mu \mathrm{A})$ & Method \\
\hline${ }^{124} \mathrm{Xe}$ & $30+$ & 211 & Gas \\
${ }^{124} \mathrm{Xe}$ & $42+$ & 1 & Gas \\
${ }^{209} \mathrm{Bi}$ & $31+$ & 300 & HiT oven \\
${ }^{209} \mathrm{Bi}$ & $50+$ & 5.3 & HiT oven \\
${ }^{16} \mathrm{O}$ & $6+$ & 3000 & Gas \\
${ }^{16} \mathrm{O}$ & $7+$ & 925 & Gas \\
${ }^{40} \mathrm{Ca}$ & $11+$ & 400 & LoT oven \\
\hline \hline
\end{tabular}

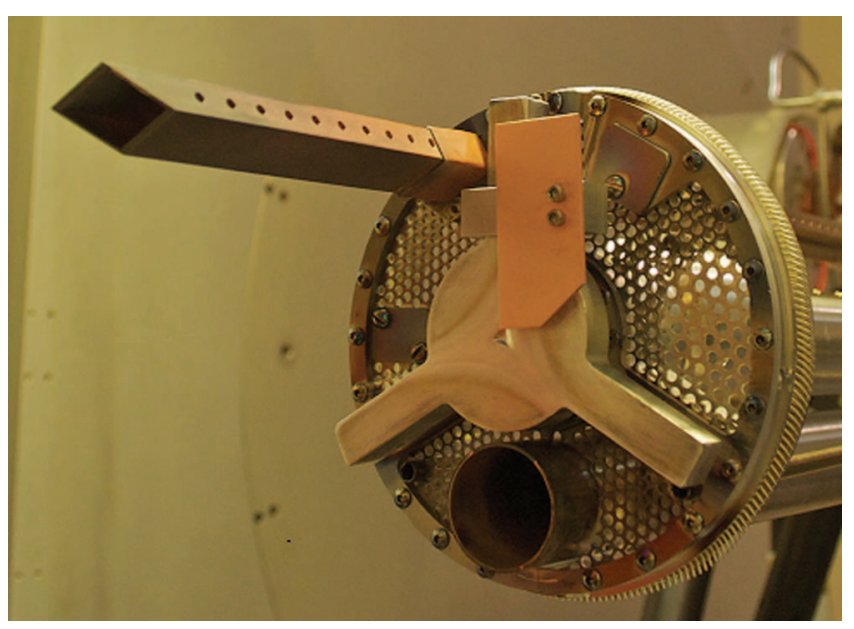

FIG. 8. (Color online) The injection end of the VENUS ECR ion source. The $18 \mathrm{GHz}$ waveguide is shown near the top of the screen structure with a waveguide extension, which has a beveled transition. $28 \mathrm{GHz}$ is fed through the round waveguide shown at the bottom of the RF screen structure below the bias disk. 


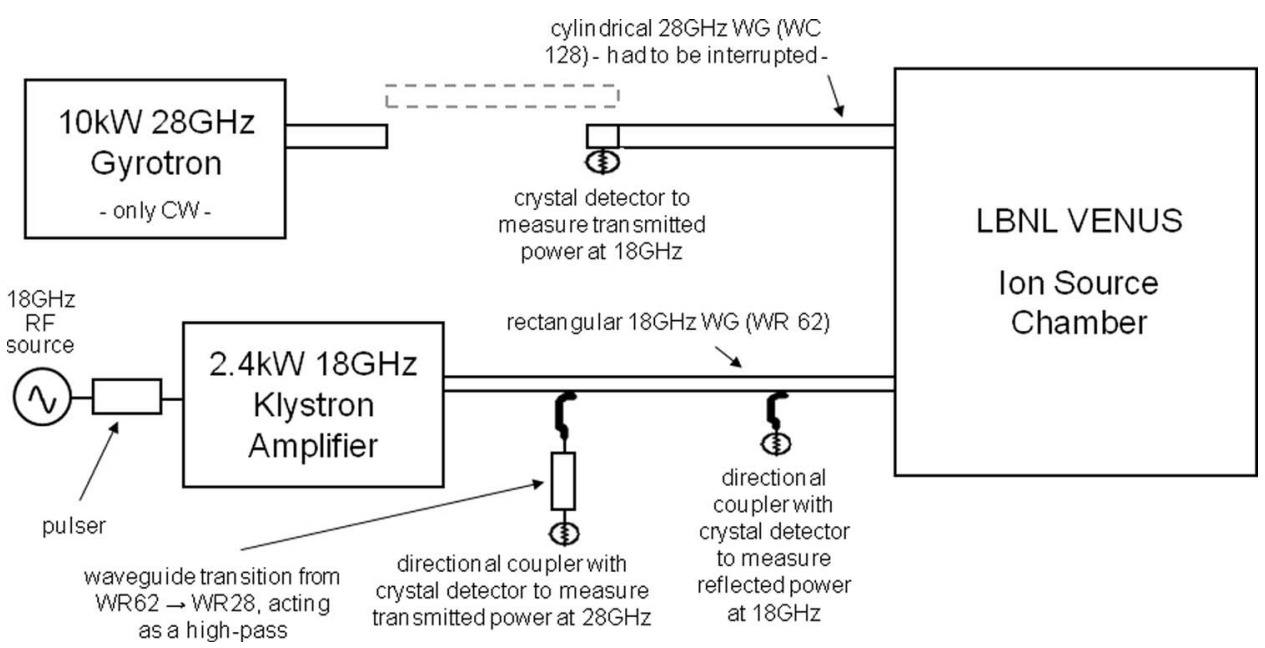

FIG. 9. A schematic diagram of the VENUS waveguide system showing the modifications used to measure the transmitted $18 \mathrm{GHz}$ signal.

shown in Fig. 9 and a pulser was added to the $18 \mathrm{GHz}$ amplifier chain. This made it possible to measure the time response of the reflected $18 \mathrm{GHz}$ power in coincidence with the $18 \mathrm{GHz}$ power transmitted out through the $28 \mathrm{GHz}$ waveguide. It was also possible to measure the $28 \mathrm{GHz}$ power transmitted out through the $18 \mathrm{GHz}$ waveguide, but the gyrotron power can only be ramped slowly, which does not make it possible to pulse the power at $28 \mathrm{GHz}$.

An extensive set of measurements was done on VENUS using the microwave configuration described above. It is beyond the scope of this paper to describe all of the results, rather one data set, which shows some of the interesting phenomena observed, will be discussed here. In Figs. 10(a) and 10(b) the transient responses of the reflected and transmitted power are shown for a $340 \mathrm{~W} 18 \mathrm{GHz}$ pulse. The RF is switched off for $2.5 \mathrm{~s}$ to extinguish the plasma from the previous pulse and then at $\mathrm{t}=0$ it is switched on for $2.5 \mathrm{~s}$. At turn on, RF fields rise rapidly and reach initial equilibrium in a few $\mu$ s as shown by the rapid rise of the transmitted power. During the first $0.6 \mathrm{~ms}$ the plasma chamber has no discernable plasma absorption and it acts as an over-coupled, over-moded high Q cavity. At $0.6 \mathrm{~ms}$, the plasma begins to affect the RF fields and the transmitted power begins to oscillate and decay. At $1.12 \mathrm{~ms}$, the transmitted power goes to almost zero, indicating that the RF fields have collapsed due to the build up of plasma density and its associated loading. After a few more oscillations in the reflected and transmitted power, the transmitted power drops again to very low levels, indicating the RF fields are now quite low. Over a longer time period shown in Fig. 10(b), the reflected and the transmitted power rise slowly and then saturate after about $200 \mathrm{~ms}$.

When the transmitted power drops to low levels, the injected $18 \mathrm{GHz}$ is being strongly absorbed by the plasma and the RF fields are probably best understood as near field power from the antenna being strongly absorbed in the first pass. Here, the plasma chamber walls play a secondary role. The reflected signal remains greater than 0 at all times during these transients and at $\mathrm{t}>1.5 \mathrm{~ms}$ the reflection coefficient $(\mathrm{Pr} / \mathrm{Pi})$ is only about $1 \%-2 \%$ which is typical of the reflection coefficient for the beveled antenna in free space.
The transient transmission measurements show that the buildup of very high RF fields before the plasma loading occurs is an important part of the preglow dynamics. ${ }^{7}$ Likewise, the strong absorption that follows, especially at about $1.5 \mathrm{~ms}$, where the transmitted signal is roughly only $4 \%$ of its initial value at turn on, indicates that the RF field levels are reduced about $1 / 5$ their initial values. The long slow rise of the transmitted power shown in Fig. 10(b) indicates a small increase in the RF field strength, but why the time constant for this rise is so long is unclear at this stage.

The very strong absorption of RF power in the CW situation by the plasma indicates that it is unrealistic to model this as coupling to a high $\mathrm{Q}$ cavity with distinct cavity modes. ${ }^{8}$ This is especially important in understanding RF coupling in over-moded cavities where the diameter to free space wavelength is greater than 4 . In this case, it is more appropriate to discuss the rf coupling to the plasma as single pass and multi-pass adsorption of injected waves ${ }^{1}$ rather than as an ensemble of cavity modes. Here, the near field pattern of the injection waveguide will be critical in determining the RF coupling.

Unlike the $18 \mathrm{GHz}$ injected in $\mathrm{TE}_{11}$ mode, the present $28 \mathrm{GHz}$ injection in VENUS uses a $35 \mathrm{~mm}$ diameter round waveguide in the $\mathrm{TE}_{01}$ mode shown in Fig. 8. The $\mathrm{TE}_{01}$ mode has a hollow RF power distribution with no RF power on axis, a maximum power density at $48 \%$ of waveguide radius and zero power at full radius. While this mode is ideal for low loss in the transmission line between the gyrotron and VENUS, it does not appear to be the best choice for coupling to the ECRIS plasma. In many plasma fusion devices, wave guide components are used to transform $\mathrm{RF}$ power from $\mathrm{TE}_{01}$ mode to either a $\mathrm{TE}_{11}$ or $\mathrm{HE}_{11}$ mode before directing it onto the ECR location. ${ }^{9}$ Analysis of how to modify the injection geometry of the VENUS $28 \mathrm{GHz}$ system to adopt this technique is now underway. Two methods are being considered. The first would convert the incoming $28 \mathrm{GHz} \mathrm{TE}_{01}$ mode to a $\mathrm{HE}_{11}$ mode using waveguide components as was done on the Wisconsin HSX Stellerator. ${ }^{10}$ The second more complex method would be to convert the $28 \mathrm{GHz}$ into a quasi-Gaussian beam and use mirrors to direct the power. ${ }^{11}$ In any case, 

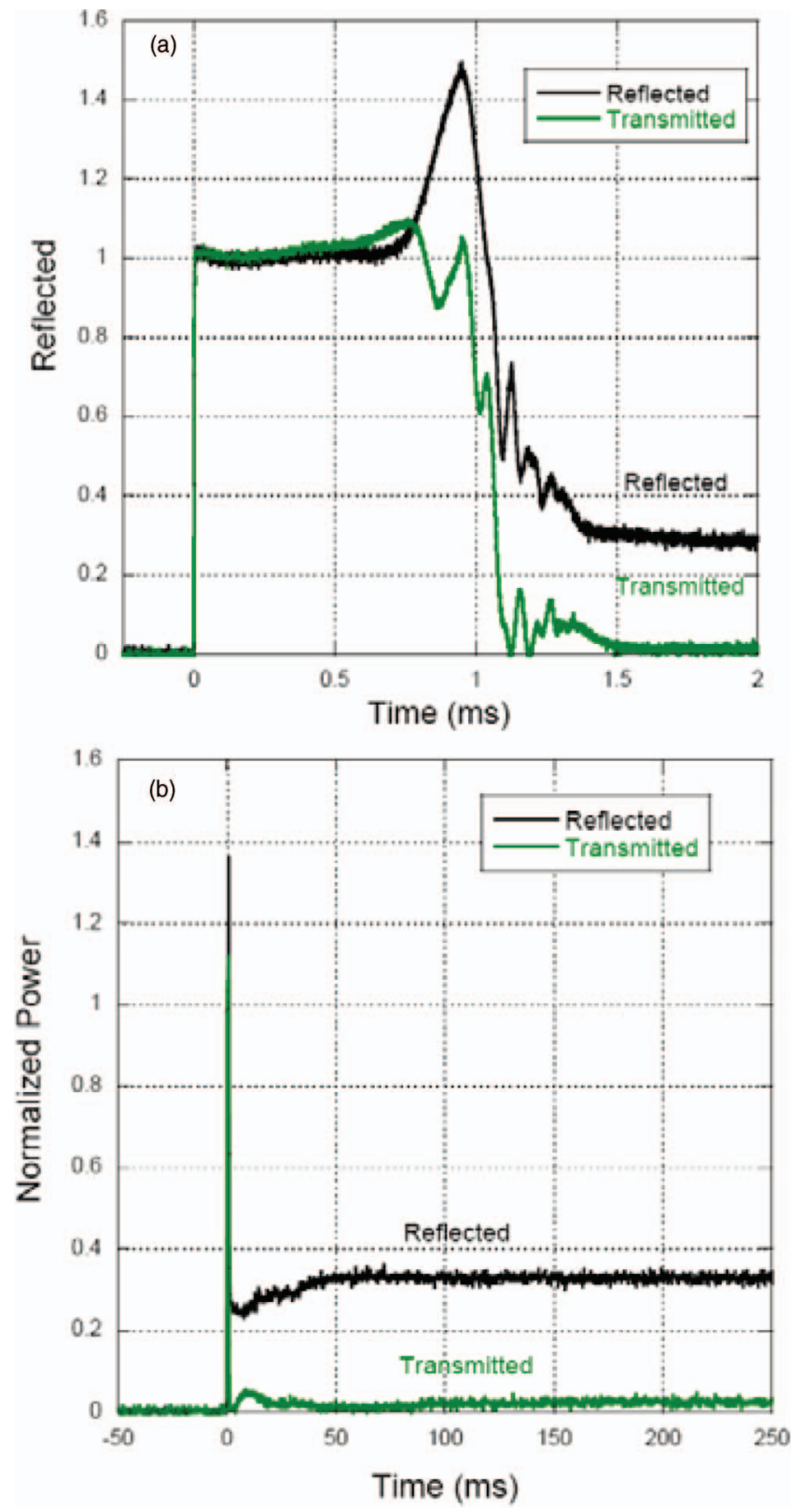

FIG. 10. (Color online) (a) The transient behavior of the reflected and transmitted power for the first few ms after RF is turned on. The reflected and transmitted power curves are normalized to 1 at $\mathrm{t}=0+$ and are shown for $340 \mathrm{~W}$ of $18 \mathrm{GHz}$ switched on at $\mathrm{t}=0$. (b) After reaching a minimum at about $10 \mathrm{~ms}$, the reflected power slowly increases over the next $50 \mathrm{~ms}$. The transmitted power also shows some relatively slow changes in the first $150 \mathrm{~ms}$. improving the coupling of the $28 \mathrm{GHz}$ to the plasma in VENUS has the potential to significantly improve its performance, since qualitatively the $18 \mathrm{GHz}$ RF injected in the TE11 mode appears to couple more efficiently than the $28 \mathrm{GHz} \mathrm{RF}$ injected in the TE01 mode.

\section{FUTURE WORK}

The performance of VENUS continues to improve and work is ongoing to expand its range of capabilities. Near term plans include the development of high intensity uranium beams and high efficiency ${ }^{48} \mathrm{Ca}$ beams, as well as a modification to improve the coupling of the $28 \mathrm{GHz}$ to the plasma.

\section{ACKNOWLEDGMENTS}

This work was supported by the Director, Office of Science, of the U.S. Department of Energy under Contract No. DE-AC02-05CH11231.

${ }^{1}$ R. Geller, Electron Cyclotron Resonance Ion Sources and ECR Plasmas, edited by R. Geller (Institute of Physics, Bristol, 1996), p. 212.

${ }^{2}$ C. Lyneis, D. Leitner, D. S. Todd, G. Sabbi, and S. Prestemon, Rev. Sci. Instrum. 79, 02A321 (2008)

${ }^{3}$ D. Leitner-Wutte, M. A. McMahan, D. Argento, T. Gimpel, A. Guy, J. Morel, R. Siero, R. Thatcher, and C. M. Lyneis, Heavy ion cocktail beams at the 88-inch cyclotron, LBNL Paper LBNL-51451, Lawrence Berkeley National Laboratory, 2010, see http://www.escholarship.org/uc/ item/65x4t87p.

${ }^{4}$ D. Leitner, C. M. Lyneis, M. Leitner, A. Hodgkinson, T. Loew, P. Ferracin, G. L. Sabbi, G. Machicoane, and E. Pozdeyev, Status of the VENUS ECR ion source, Proceedings of the 19th International Workshop on ECR Ion Sources, Grenoble, 23-26 August 2010; JACoW: http://www.jacow.org/.

${ }^{5}$ T. Loew, S. Abbott, M. Galloway, D. Leitner, and C. M. Lyneis, "Design of a High Temperature Oven for an ECR Source for the Production of Uranium Ion Beams," Proceedings of the Particle Accelerator Conference, Albuquerque, New Mexico, 25-29 June 2007.

${ }^{6}$ Dalton Electric Heating Co., Inc., Cartridge Heater and Platen Heater Manufacturer-Dalton Electric, 07 August 2011, see http://www. daltonelectric.com.

${ }^{7}$ P. Sortais, J.-L. Bouly, J.-C. Curdy, T. Lamy, P. Sole, T. Thuillier, J.-L. Vieux-Rochaz, and D. Voulot, Rev. Sci. Instrum. 75, 1610 (2004).

${ }^{8}$ S. Gammino, G. Ciavola, L. G. Celona, D. Mascali, and F. Maimone, IEEE Trans. Plasma Sci. 36(4), (2008).

${ }^{9}$ M. Thumm, Int. J. Electron. 57(6), 1225 (1984).

${ }^{10}$ D. T. Anderson, J. Radder, and K. Likin, University of Wisconsin HSX project, private communication (August 2011).

${ }^{11}$ V. Erckmann, Fusion Eng. Des. 84, 131 (2009). 